\title{
Impact of Resistance Training on FEV1 and Functional Exercise Capacity among COPD Patients: A Meta-analysis
}

\author{
Muhammad Ather Hashmi, Syed Abid Mehdi Kazmi and Saima Ali \\ College of Rehabilitation Sciences, Ziauddin University, Karachi, Pakistan
}

\begin{abstract}
Chronic obstructive pulmonary disease (COPD) is the third leading cause of mortality and morbidity across the Globe. A meta-analysis was conducted to determine the effectiveness of different modes of resistance training on FEV1 and functional exercise capacity among COPD patients. Data bases of Cochrane, PEDro, Embase, CINAHL, PubMed and Google Scholar were searched seeking research articles of interest. All those studies were included in which effect of resistance training was determined on FEV1 and functional exercise capacity of COPD patients and published in English language. All those studies that predated to 2011 were excluded from the review. A sample of 180 COPD patients was included in 5 RCTs. Results of the study demonstrated that resistance training has a mild pool effect in increasing FEV1 with an effect size of (SMD) of 0.160 ( $95 \% \mathrm{Cl}$ of -0.840 to 0.521 ) calculated at random effect model, $\mathrm{I}^{2}=62.99 \%(95 \% \mathrm{Cl}$ of 0.00 to 89.42$)$; whereas, functional exercise capacity demonstrated large pool effect size $0.886(95 \% \mathrm{Cl}$ of 0.401 to 1.371$)$ with $\mathrm{I}^{2}=0.0(95 \% \mathrm{Cl}$ of 0.00 to 0.00$)$.

The study concludes that there is a small to large impact of resistance exercises in improving functional exercise capacity and forced expiratory volume.
\end{abstract}

Key Words: Resistance training, 6-minute walk test 6MWT, Chronic obstructive pulmonary disease, Functional exercise capacity, Forced expiratory volume.

How to cite this article: Hashmi MA, Kazmi SAM, Ali S. Impact of Resistance Training on FEV1 and Functional Exercise Capacity among COPD Patients: A Meta-analysis. J Coll Physicians Surg Pak 2022; 32(01):68-74.

\section{INTRODUCTION}

Chronic obstructive pulmonary disease (COPD) is counted as the third most common cause of morbidity and disability with 251 million cases per anum reported worldwide. ${ }^{1,2}$ Previously, COPD was ranked as fourth among the common causes of mortality with an estimated three million annual deaths worldwide, but recent studies has ranked COPD was the third leading cause of death globally. ${ }^{2,3}$ According to World Health Organisation, COPD, deaths are more prevalent among the low socio-economic developing countries, estimated up to $90 \%$ of the total mortality rate across the Globe. ${ }^{2}$ In Asia, $13.5 \%$ of the total population suffers with COPD. Particularly, in Pakistan every $10^{\text {th }}$ individual suffers with COPD, out of which $19.4 \%$ are of age above 40 years. ${ }^{4}$ Moreover, the problem has been identified as a growing public health concern and a challenge for the clinicians of $21^{\text {st }}$ Century. ${ }^{5}$

Correspondence to: Dr. Muhammad Ather Hashmi, College of Rehabilitation Sciences, Ziauddin University, Karachi, Pakistan

E-mail: ather.hashmi@zu.edu.pk

Received: June 10, 2021; Revised: August 27, 2021;

Accepted: October 06, 2021

DOI: https://doi.org/10.29271/jcpsp.2022.01.68
Standardised guidelines suggest that the patients above the age of 35 years with the history of smoking, accompanied with symptoms like exertion, difficulty in breathing, chronic productive cough with wheezing and reduced exercises tolerance are to be susceptible of being diagnosed as COPD. ${ }^{6}$ Consequently, the severity of the condition of patients is further deteriorated by exacerbations or comorbidities, and significant economic burden due to the hospitalisation, absence from work, and disability. ${ }^{7}$ Corresponding to this, COPD management, including medication and recurrent hospitalisation, cost from $\$ 1,544$ to $\$ 2,335$ in Asian countries, annually. ${ }^{8}$ A number of pharmaceutical and non-pharmaceutical treatment options are counted in management of COPD patients; however, studies advocated the effectiveness of multi-disciplinary as well as multi-treatment care programme for the patients with COPD. ${ }^{9}$ However, pulmonary rehabilitation has been conferred as the cornerstone in management of COPD by NICE guidelines, emphasising the importance of pulmonary rehabilitation for all individuals presenting with COPD; even those who have acutely suffered an exacerbation, or underwent recent hospitalisation. ${ }^{6}$ Moreover, pulmonary rehabilitation programme that comprises of customised and structured exercises patterns, regimes and awareness for self-care, improves COPD symptoms and exercise tolerance; and reduces expenditure of resources on recurrent hospitalisation and length of stay. ${ }^{10}$ Resistance training has demonstrated better improvement in muscular strength than endurance exercise and causes lesser chances of dyspnea, 
while performing activities. ${ }^{11}$ Therefore, resistance training is more tolerable than endurance exercise regime. Researches show evidently upon that combining the protocol of resistance and endurance training has shown significant increase in the respiratory parameters. ${ }^{12}$

\section{METHODOLOGY}

The meta-analysis was performed as per the guidelines of preferred reporting items for systematic reviews and meta-analyses (PRISMA).

Eligibility criteria defined as all those studies that evaluate the effect of resistive exercise training on respiratory functionality, functional exercise capacity and health-related quality of life among the individuals suffering with COPD were incorporated for the review. All the research articles included in the review were published in English and searched with the vocabulary controlled keywords including chronic pulmonary obstructive disease, COPD, resistance training, anaerobic exercise, pulmonary function, FEV1, FVC, minute ventilation, and functional capacity.

An electronic search was generated to identify the reaches evaluating the effectiveness of resistance exercises on respiratory function, health-related quality of life and exercises, capacity of COPD patients on various online data bases such as Cochrane, PeDro, Embas, Cinhrl, Pubmed and Google Scholar. All the studies meeting eligibility criteria and published between 2015 and 2020 were incorporated into the review at first. However, due to the insufficient number of studies matching the subject preset tenure of publication, researches published from 2010 to 2020 were taken in account, too.

Experimental studies were electronically selected to perform systematic review with the target population of COPD patients, intervention of resistance exercise training with elastic resistance bands, dumbbells or any other type of resistance comparing with aerobic or endurance training that is either provided alone or in combination with resistance or any other modality; and outcome measures including pulmonary function, exercise capacity and health status. Preferably, randomised controlled trials were prioritised. However, due to limited availability of literature on desired subject, a quasi-experimental study was also included.

Each article was reviewed by the author to check if the title and the content of the selected study match with the inclusion and exclusion criteria. Finally, descriptive data was extracted from the selected studies into a standardised table under the headings including name of first author along with year of publication, total sample size and count of individuals recruited in experimental and control groups, intervention with duration, mode and frequency, outcome measures and results as represented in Tablel.

Risk of bias was evaluated among the studies by using standard checklist of Cochrane, considering five domains including random sequence generation, allocation concealment, blinding of partici- pants, blinding of outcome assessor, and reporting bias. Each study was designated as high, moderate or low for each of the said categories.

Qualitatively, data was analysed using MedCalc software through the difference of standardised means (SMD) to estimate the pool effect of random effect model keeping $\mathrm{I}^{2}$ at $95 \%$ of $\mathrm{Cl}$. Hedge $\mathrm{G}$ statistics was used to formulate a forest plot and table of SMD to interpret the findings in accordance of Cohen's rule of thumb that designate values of $0.2,0.5$ and 0.8 as small, medium and greater effect size, respectively. Level of heterogeneity was calculated by using percentile of heterogeneity and Cochrane Q.

\section{RESULTS}

Originally, a total of 17,400 articles were searched through an electronic search strategy that include 16,520 from Google scholar, 337 from Cochrane, 282 from PubMed, 170 from Embase, 81 from PEDro, nine from Medline and one study from CINAHL. Further, screening was performed on the basis full-text availability, duplication, language and relevancy to the topic and date of publication that filtered out 642 including randomised controlled trials and quasi-experimental studies. However, after full-text screening nine studies met the inclusion selected specifying RCTs and quasi-experimental studies investigating the effectiveness of resistive exercises on COPD patients in comparisons with aerobic exercises regimes as illustrated in.

Records of 361 patients were retrieved from nine studies. However, due to heterogeneity of outcome measures among selected studies, meta-analysis was performed on three studies for FEV1 and two studies for 6MWT.

The findings of meta-analysis out of 3 studies on collectively 107 patients revealed small effect size as per the Cohen's rule of thumb, for the impact of resistance training on Force expiratory volume in $1^{\text {st }}$ second of expiration through SMD, showing impact of $0.160(95 \% \mathrm{Cl}$ of -0.840 to 0.521$)$ in random effect model among the COPD patients as shown in Table II. Moreover, this effect size is further enthralled in the forest plot with $95 \%$ confidence interval in random effect model as shown in Figure 2.

$I^{2}$ was used to measure out the percentage of heterogeneity. However, percentages of inconsistencies between the SMD of included researches was calculated through Cochrane Q, considering the value of $\mathrm{I}^{2}=62.99 \%(95 \% \mathrm{Cl}$ of 0.00 to 89.42 ) with $\mathrm{Q}=5.4041$ as demonstrated in Table III.

This meta-analysis conducted for determining the pool effect size of resistance exercise training on 6 minute walk test score of collectively 73 COPD patients, reported in two studies, which showed significant improvement in comparison to the control group. Eventually, the pool event size for the impact of resistance training showed large effect size according to the Cohen's rule of thumb with SMD of $0.886(95 \% \mathrm{Cl}$ of 0.401 to 1.371$)$ in both random effect model and fixed effect model as shown Table IV. Moreover, these results are further intrigued in the forest plot, showing an increasing trend in the scores of 6 minute walk test by performing resistance exercise in the Figure 3. 
Table I: Characteristic of studies included in meta-analysis.

\begin{tabular}{|c|c|c|c|c|c|c|c|c|}
\hline S. No. & Author & Group & $\mathbf{N}$ & $\begin{array}{c}\text { Target } \\
\text { population }\end{array}$ & Intervention & Outcome measures & Results & p-value \\
\hline \multirow{2}{*}{1} & \multirow{2}{*}{$\begin{array}{l}\text { Edvardsen E } \\
(2014)^{13}\end{array}$} & Training & 30 & \multirow{2}{*}{ COPD } & \multirow{2}{*}{$\begin{array}{c}\text { High-intensity endurance and strength } \\
\text { training (60 min, three times a week, } 20 \\
\text { weeks) }\end{array}$} & \multirow{2}{*}{$\begin{array}{l}\text { Minute ventilation, FEV1, } \\
\text { TLCo, PO Uptake }\end{array}$} & \multirow{2}{*}{$\begin{array}{l}\text { Significant } \\
\text { results for PO } \\
\text { Uptake and, } \\
\text { Tlco, non- } \\
\text { significant for } \\
\text { FEV1, MVV }\end{array}$} & \multirow{2}{*}{$\begin{array}{l}0.002 \\
0.007 \\
0.738 \\
0.064 \\
\text { resp. }\end{array}$} \\
\hline & & control & 31 & & & & & \\
\hline \multirow{3}{*}{2} & \multirow{3}{*}{$\begin{array}{l}\text { Zambom- } \\
\text { Ferraresi F } \\
(2015)^{14}\end{array}$} & $\begin{array}{l}\text { Combined } \\
\text { training }\end{array}$ & 14 & \multirow{3}{*}{ COPD } & $\begin{array}{c}12 \text { weeks, I d / week resistance \&1d / } \\
\text { week endurance training }\end{array}$ & $\begin{array}{l}\text { Pulmonary function (FEV1, } \\
\text { FVC, FEV1/FVC, TCL) }\end{array}$ & \multirow[b]{2}{*}{ Non-significant } & \multirow[b]{2}{*}{$>0.05$} \\
\hline & & $\begin{array}{l}\text { Resistance } \\
\text { training }\end{array}$ & 14 & & 12 weeks, $2 \mathrm{~d} /$ week resistance training & $\begin{array}{l}\text { Mean Inspiratory Pressure } \\
\text { and Mean Expiratory } \\
\text { Pressure }\end{array}$ & & \\
\hline & & Control & 8 & & & $\begin{array}{l}\text { Functional Capacity, Muscles } \\
\text { Strength, Quality of life } \\
\text { (BODE) }\end{array}$ & Significant & $<0.05$ \\
\hline \multirow{3}{*}{3} & \multirow{3}{*}{$\begin{array}{l}\text { Vonbank K } \\
(2012)^{15}\end{array}$} & $\begin{array}{l}\text { Endurance } \\
\text { training }\end{array}$ & 12 & \multirow{3}{*}{ COPD } & $\begin{array}{c}\text { Cycle ergometer twice / week tolat duran } \\
60 \text { min intensity } 60 \% \\
\end{array}$ & \multirow{3}{*}{$\begin{array}{l}\text { Pulmonary function (FEV1 } \\
\text { and FEV1/FVC) and } \\
\text { cardiopulmonary exercises } \\
\text { testing }\end{array}$} & \multirow{3}{*}{ Not significant } & \multirow{3}{*}{$>0.05$} \\
\hline & & $\begin{array}{l}\text { Progressive } \\
\text { strength } \\
\text { traininig }\end{array}$ & 12 & & $\begin{array}{c}\text { Twice/ week } 8-15 \text { rep / set (leg press, } \\
\text { bench press, bench pull) }\end{array}$ & & & \\
\hline & & Combination & 12 & & Both combined & & & \\
\hline \multirow[b]{2}{*}{4} & \multirow{2}{*}{$\begin{array}{l}\text { Silva e Silva } \\
\text { CM } \\
(2018)^{16}\end{array}$} & $\begin{array}{l}\text { Control } \\
\text { Group }\end{array}$ & 25 & \multirow[b]{2}{*}{ COPD } & $\begin{array}{l}\text { Warm-up, aerobic exercise, inspiratory } \\
\text { muscle training, and session stretching, } \\
\text { followed by massage therapy }\end{array}$ & \multirow{2}{*}{$\begin{array}{c}\text { Functional exercise capacity } \\
\text { (6MWT), respiratory muscle } \\
\text { strength (MIP, MEP), upper } \\
\text { limb strength (MR), dysnea } \\
\text { (mMRC), quality of life } \\
\text { (SGRQ) }\end{array}$} & \multirow{2}{*}{$\begin{array}{l}\text { Significant in } \\
\text { 6MWT, MIP, MR } \\
\text { \& SGRQ }\end{array}$} & \multirow{2}{*}{$\begin{array}{c}\text { p-values } \\
0.043 \\
0.001 \\
0.027 \\
0.000\end{array}$} \\
\hline & & $\begin{array}{l}\text { Treatment } \\
\text { Group }\end{array}$ & 26 & & $\begin{array}{l}\text { Warm-up, aerobic exercise, inspiratory } \\
\text { muscle training, three sets of upper } \\
\text { limb resistance exercise, and session } \\
\text { stretching, followed by massage } \\
\text { therapy }\end{array}$ & & & \\
\hline
\end{tabular}

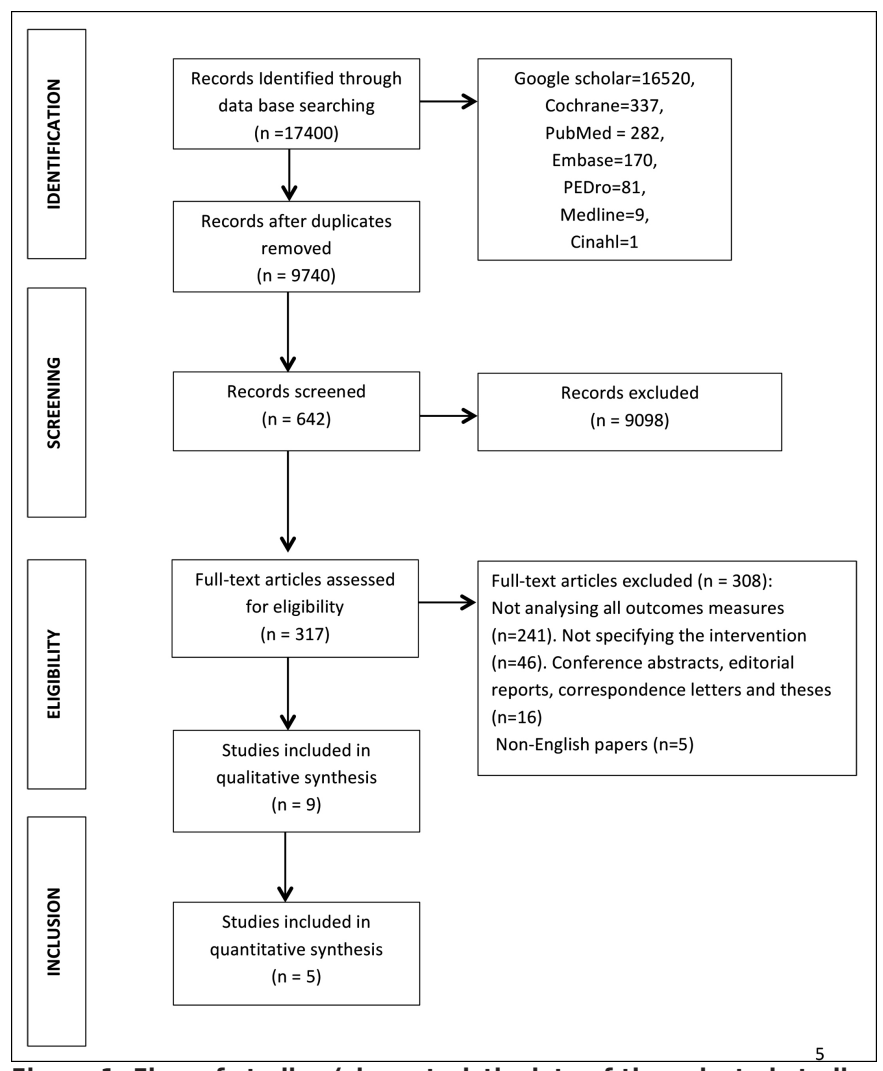

Figure 1: Flow of studies (characteristic data of the selected studies is demonstrated in Table I).

$\mathrm{Q}$ and $\mathrm{I}^{2}$ test was applied in order to estimate the statistical heterogeneity. $Q=0.347$ and $I^{2}=0.00$ suggested no incon- sistency on both random and fixed models on $95 \%$ confidence interval as mentioned in Table V.

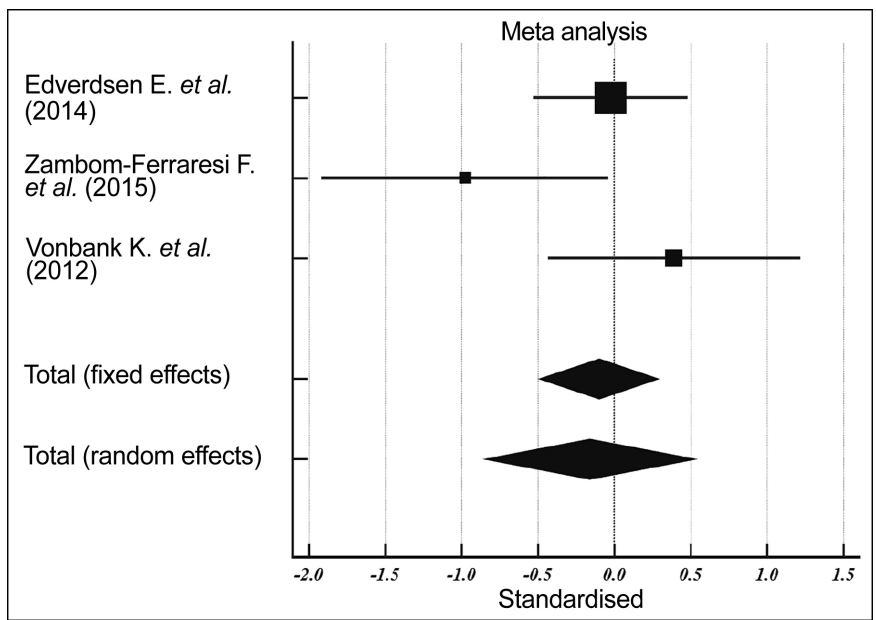

Figure 2: Forest plot indicating fixed and random effect model for FEV1.

Qualitative analysis revealed significant impact of resistance exercises regime on functional exercise capacity in studies. While none of the included studies showed significant improvement in overall pulmonary function in response to resistance training except for one study (Edvardsen et al.), which showed significant improvement in the total lung capacity of the patients in experimental group ( $p$-value $<0.05$ ). The same study also signifies the results of PO uptake in training group. Furthermore, three researches advocated the significant improvement in the status of quality of like on either SGRQ or BODE index. 
Table II: Demonstrating the findings of FEV1 meta-analysis.

\begin{tabular}{|c|c|c|c|c|c|c|c|c|c|c|}
\hline \multirow{2}{*}{ Study } & \multirow{2}{*}{ N1 } & \multirow{2}{*}{ N2 } & \multirow{2}{*}{ Total } & \multirow{2}{*}{ SMD } & \multirow{2}{*}{ SE } & \multirow{2}{*}{$95 \% \mathrm{Cl}$} & \multirow{2}{*}{$\mathbf{T}$} & \multirow{2}{*}{$\mathbf{P}$} & \multicolumn{2}{|c|}{ Weight (\%) } \\
\hline & & & & & & & & & Fixed & Random \\
\hline Edvardsen E et al., 2014 & 30 & 31 & 61 & -0.0249 & 0.253 & -0.531 to 0.481 & & & 58.23 & 41.28 \\
\hline Zambom-Ferraresi F et al., 2015 & 14 & 8 & 22 & -0.978 & 0.451 & -1.919 to -0.0370 & & & 18.29 & 27.72 \\
\hline Vonbank K et al., 2012 & 12 & 12 & 24 & 0.392 & 0.398 & -0.434 to 1.218 & & & 23.48 & 31.00 \\
\hline Total (fixed effects) & 56 & 51 & 107 & -0.101 & 0.193 & -0.484 to 0.281 & -0.525 & 0.601 & 100.00 & 100.00 \\
\hline Total (random effects) & 56 & 51 & 107 & -0.160 & 0.343 & -0.840 to 0.521 & -0.466 & 0.642 & 100.00 & 100.00 \\
\hline
\end{tabular}

Table III: Test of heterogeneity for FEV1.

\begin{tabular}{|l|l|}
\hline $\mathrm{Q}$ & 5.4041 \\
\hline $\mathrm{DF}$ & 2 \\
\hline Significance level & $\mathrm{p}=0.0671$ \\
\hline $\mathrm{I}^{2}$ (inconsistency) $^{\text {(in }}$ & $62.99 \%$ \\
\hline $95 \% \mathrm{Cl}$ for $\mathrm{I}^{2}$ & 0.00 to 89.42 \\
\hline
\end{tabular}

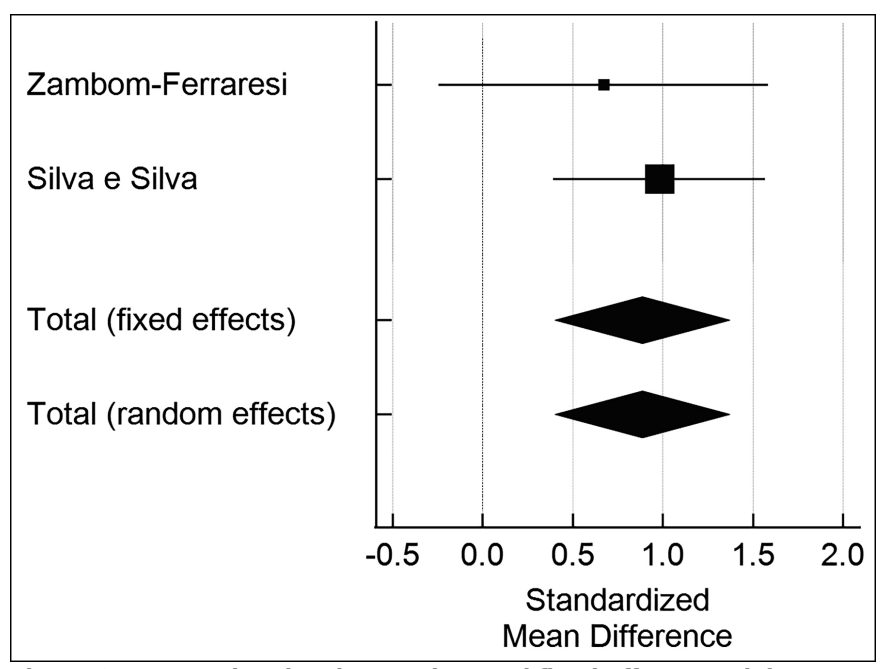

Figure 3: Forest plot showing random and fixed effects model.

Overall assessment for the risk of bias was performed by using standardised checklist of Cochrane for risk of bias including selection bias, attrition bias, reporting bias, and bias in the performance for all the studies taken in account to perform meta-analysis assessing random sequencing, concealment of participants allocation into groups, masking of participants, interventionists and outcome assessors; and selective reporting of data upon the authors judgement as shown in Table VI and further illustrated in Figure 4.

\section{DISCUSSION}

The meta-analysis conducted upon FEV1 demonstrated small pool side effect for the resistance training in improving the FEV1 with an effect size of 0.160 ( $95 \% \mathrm{Cl}$ of -0.840 to 0.521$)$, which was calculated with random effect model considering the value of $62.99 \%(95 \% \mathrm{Cl}$ of 0.00 to 89.42$)$ on random effect model in comparison endurance training. Correspondingly, Liao et al. also reported similar effects of resistance training on FEV1. ${ }^{17}$ Nevertheless, their findings are reported in terms of FEV1 absolute and FEV1 as percentile of predicted values. ${ }^{17}$ FEV1 absolute showed no significant impact of resistance training over comparative groups in improving FEV1 with WMD of 0.17 at $95 \% \mathrm{Cl}$ of 0.01 to 0.35 , and heterogeneity $I^{2} 0 \%(p=0.07)$. Contrariwise, FEV1 in terms of percentile of predicted $\%$ showed statistically significant pool effect size for resistance training group with WMD of $6.88 \%$ at $95 \%$ $\mathrm{Cl}$ of $0.41-13.35 \%$ and heterogeneity $\mathrm{I}^{2} 0 \%,(p=0.04){ }^{17}$

However, meta-analysis for the impact of resistance exercise training on exercise capacity in terms of 6 minute walk test deduced significant results with large effect size SMD of $0.886(95 \% \mathrm{Cl}$ of 0.401 to 1.371$)$ in both random and fixed effect model with $0.00 \%$ inconsistencies as $I^{2}=0.00$ at $95 \%$ confidence interval. Consequently, meta-analysis findings for functional exercise capacity ( 6 minute walk test), therefore, corresponds to results of meta-analysis, performed in the 2019 by Li et al., showing significant improvement in scores of 6 minute walk test among the COPD patients performed resistance training with WMD, 54.52 at $95 \% \mathrm{Cl}$ of $25.47-83.56 .{ }^{18}$ However, level of heterogeneity reported by $\mathrm{Li}$ et al. was $\mathrm{I}^{2}=43 \%(p=0.14)$, conversing to present study findings of $\mathrm{I}^{2}=0.00 \%$, which indicate more accurate findings for the similar impact trend that might be insignificantly affected by the difference in the number of studies included by Li et al., but excluded in this review as predating to the criterion for inclusion. ${ }^{18}$ In contrast to this, meta-analysis published by Liao et al. reported non-significant effect of resistance training in improving scores of 6 minute walk test with WMD of $1.83 \mathrm{~m}, 95 \% \mathrm{Cl}$ of 15.32 to 18.97 , and heterogeneity level of $\mathrm{I}^{2}=0 \%(\mathrm{p}=0.83) .{ }^{17} \mathrm{In}$ addition to this, Lima et al. 2020 reported an uncertain effect size of resistance training in comparison with no-exercise control group with a mean difference (MD) of 17.13 at $95 \% \mathrm{Cl}$ of -6.33 to 40.58 and heterogeneity $\mathrm{I}^{2}=57 \%{ }^{19}$ Similarly, meta-analysis conducted by Lepsen et al. reported non-significant difference in scores of 6 minute walk test in resistance training and endurance training with mean difference (MD) $=-9.91$ at $95 \% \mathrm{Cl}$ of 31.55 to 11.73 . Consequently, there is a relative difference among the results of various meta-analyses. ${ }^{20}$

Other outcome measures that were not incorporated in meta-analysis include health- realted quality of life that was statistically found to be improved in significant manner among three of the included studies by using BODE index or St. George Respiratory Quessionarrie. 
Table IV: Demonstrating the findinsd gs of meta-anaysis for 6MWT.

\begin{tabular}{|c|c|c|c|c|c|c|c|c|c|c|}
\hline \multirow{2}{*}{ Study } & \multirow{2}{*}{ N1 } & \multirow{2}{*}{ N2 } & \multirow{2}{*}{ Total } & \multirow{2}{*}{ SMD } & \multirow{2}{*}{ SE } & \multirow{2}{*}{$95 \% \mathrm{Cl}$} & \multirow{2}{*}{$\mathbf{T}$} & \multirow{2}{*}{$\mathbf{P}$} & \multicolumn{2}{|c|}{ Weight (\%) } \\
\hline & & & & & & & & & Fixed & Random \\
\hline Zambom-Ferraresi & 14 & 8 & 22 & 0.671 & 0.438 & -0.243 to 1.585 & & & 30.81 & 30.81 \\
\hline Silva e Silva & 25 & 26 & 51 & 0.982 & 0.292 & 0.394 to 1.569 & & & 69.19 & 69.19 \\
\hline Total (fixed effects) & 39 & 34 & 73 & 0.886 & 0.243 & 0.401 to 1.371 & 3.643 & 0.001 & 100.00 & 100.00 \\
\hline Total (random effects) & 39 & 34 & 73 & 0.886 & 0.243 & 0.401 to 1.371 & 3.643 & 0.001 & 100.00 & 100.00 \\
\hline
\end{tabular}

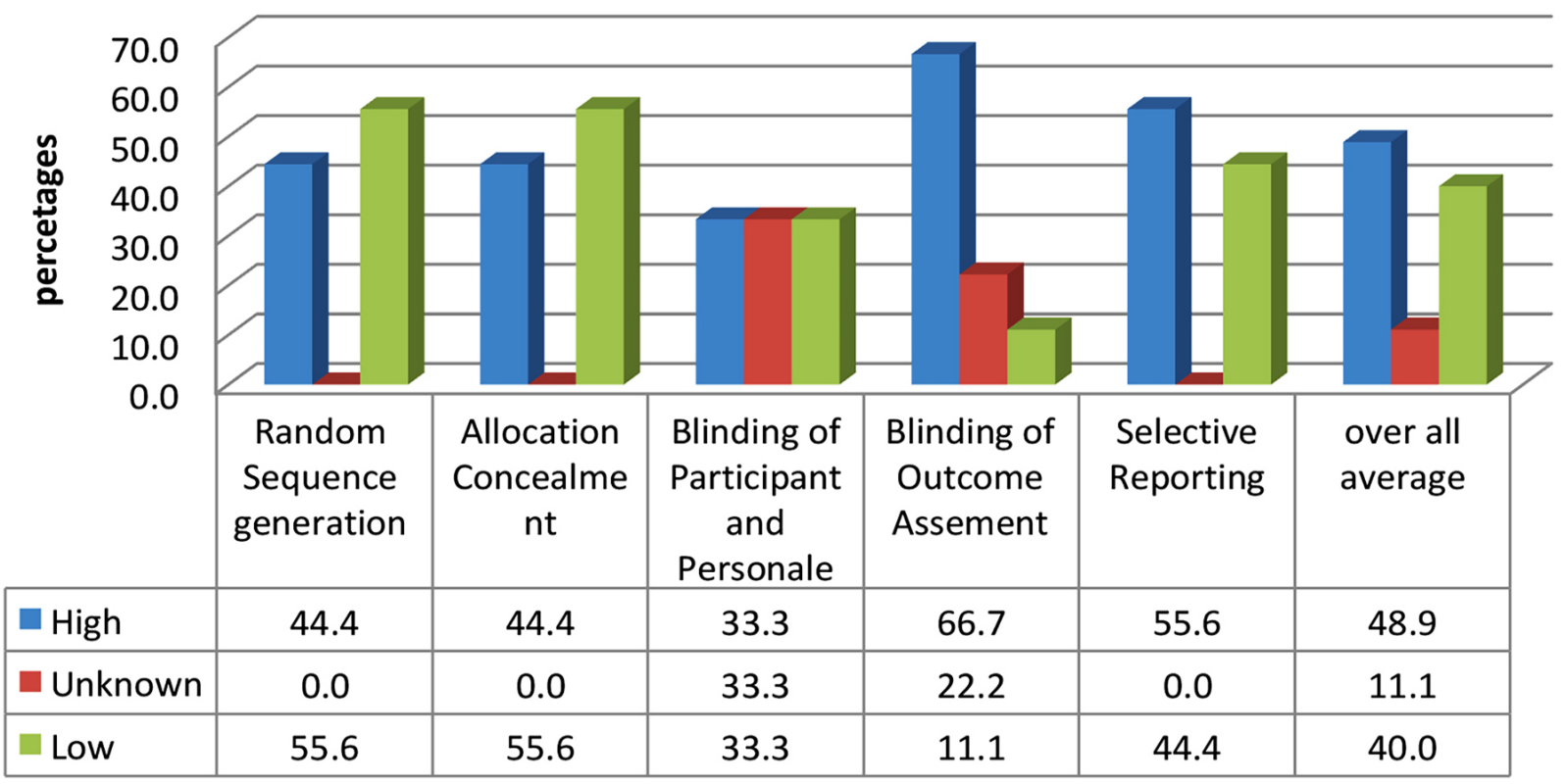

Figure 4: Author's judgement for the risk of bias.

Table V: Test of heterogeneity for 6MWT.

\begin{tabular}{|l|c|}
\hline $\mathrm{Q}$ & 0.3472 \\
\hline $\mathrm{DF}$ & 1 \\
\hline Significance level & $\mathrm{P}=0.5557$ \\
\hline $\mathrm{I}^{2}$ (inconsistency) & $0.00 \%$ \\
\hline $95 \% \mathrm{Cl}$ for $\mathrm{I}^{2}$ & 0.00 to 0.00 \\
\hline
\end{tabular}

Table VI: Authors judgement for the risk of bias within the studies.

\begin{tabular}{|c|c|c|c|c|c|c|}
\hline \multirow[b]{2}{*}{$\begin{array}{l}\text { S. } \\
\text { No. }\end{array}$} & \multirow[b]{2}{*}{ Author } & \multicolumn{2}{|c|}{ Selection Bias } & \multirow{2}{*}{$\begin{array}{l}\text { Performance Bias } \\
\text { Blinding of participant }\end{array}$} & \multirow{2}{*}{$\begin{array}{l}\text { Attrition Bias } \\
\text { Blinding of } \\
\text { outcome } \\
\text { assessment }\end{array}$} & \multirow{2}{*}{$\begin{array}{l}\text { Reporting Bias } \\
\text { Selective reporting }\end{array}$} \\
\hline & & $\begin{array}{l}\text { Random } \\
\text { sequence } \\
\text { generation }\end{array}$ & $\begin{array}{l}\text { Allocation } \\
\text { concealment }\end{array}$ & & & \\
\hline 1 & Edvardsen E & $x$ & $\checkmark$ & $\checkmark$ & $x$ & $x$ \\
\hline 2 & Zambom-Ferraresi F & $\checkmark$ & $\checkmark$ & $?$ & $\mathbf{x}$ & $\mathbf{x}$ \\
\hline 3 & Vonbank K & $\checkmark$ & $\checkmark$ & $?$ & $\mathbf{x}$ & $x$ \\
\hline 4 & Silva e Silva CM & $\checkmark$ & $\checkmark$ & $?$ & $?$ & $\mathbf{x}$ \\
\hline
\end{tabular}

In contrast to this, Lepsen et al. reported insignificant findings for the impact of resistance training on quality of life. Moreover, other publications also reported mean inspiratory and expiratory pressures, maximal heart, clinical impact, muscle strengths and bioelectrical impedance. However, due to inconsistent result for these outcomes, meta-analysis could not be performed.
Analysis for the risk of bias across the studies for FEV1 reveals moderately low risk of bias with $46.67 \%$. Similarly, risk of bias across the studies for 6 minute walk test is found low with $30 \%$ that supports the consistency of the study.

In addition to this, limitations within the studies include the small sample size; and methodological limitations, such as low response rate for the quality of life questionnaire. A 
study also reported the limitation for the blinding of outcome assessor in the late phase of trial.

\section{CONCLUSION}

Resistance exercises behold highly effective impact in increasing the functional exercise capacity, while mild effect on expiratory function (FEV1) among COPD patients. Therefore, more studies should be conducted with multiple outcome measures to further clarify the impact of exercise among COPD patients.

\section{SOURCE OF FUNDING:}

This research did not receive any specific grant from funding agencies in the public, commercial, or not for- profit sectors.

\section{ETHICAL APPROVAL:}

This study is a systematic review and meta-analysis that does not involve human and animal subject or specimen; therefore, doesn't involve any related ethical issues. There is no breach of confidentiality or any unethical act in this study.

\section{CONFLICT OF INTEREST:}

The authors declared no conflict of interest.

\section{AUTHOR'S CONTRIBUTION:}

MAH: Conducted research, conceived and analysed data and performed statistical analysis.

SAMK: Provided research material and organised data for qualitative analysis.

SA: Wrote the draft and concise risk of bias assessment. All the three authors reviewed the draft critically for final publication.

\section{REFERENCES}

1. Pothirat C, Chaiwong W, Phetsuk N. Efficacy of a simple and inexpensive exercise training program for advanced chronic obstructive pulmonary disease patients in community hospitals. J Thorac Dis 2015; 7(4):637. doi: 10.3978/j.issn.2072-1439.2015.04.13.

2. WHO. Chronic obstructive pulmonary disease (COPD) 2017 [cited 201911 November]. Available from: http://www.who.int/news-room/fact-sheets/detail/chronic-ob structive-pulmonary-disease-(copd).

3. Awokola BI, Amusa GA, Jewell C, Stolbrink M, Okello G, Finney $L$, et al. Chronic obstructive pulmonary disease (COPD) in sub-saharan Africa: A systematic review and meta-analysis. Am J Respir Crit Care Med 2021 May; 203:A3133. doi:10.1164/ajrccm-conference.2021.203.1_ MeetingAbstracts.A3133.

4. Razzaq S, Nafees AA, Irfan M, Fatmi Z, editors. Prevalence and Risk Factors of COPD in Karachi, Pakistan: Findings from the Adult Asthma Study-Karachi. ISEE Conference Abstracts; 2018.

5. Hüls A, Schikowski T. Ambient particulate matter and COPD in China: A challenge for respiratory health research. BMJ 2017; doi: 10.1136/thoraxjnl-2016-209687..
6. NICE. National Institute for Health and Care Excellence: Guideline chronic obstructive pulmonary disease, diagnosis and management. Pulmonary Rehabilitation England: NICE; 2019.

7. Sinha B, Vibha RS, Chowdhury R. An epidemiological profile of chronic obstructive pulmonary disease: A community-based study in Delhi. J Postgrad Med 2017; 63(1):29. doi: 10.4103/0022-3859.194200.

8. Rehman A, Ahmad Hassali MA, Muhammad SA, Shah S, Abbas S, Hyder Ali IAB, et al. The economic burden of chronic obstructive pulmonary disease (COPD) in USA, Europe and Asia: Results from a systematic review of the literature. Expert Rev Pharmacoecon Outcomes Res 2019; doi: 10.1080/14737167.2020.1678385.

9. Brooke M, Spiliopoulos N, Collins M. A review of the availability and cost effectiveness of chronic obstructive pulmonary disease (COPD) management interventions in rural Australia and New Zealand. Rural Remote Health 2017; 17(3). doi: 10.22605/RRH4017.

10. Bermingham S. Pulmonary rehabilitation setting for adults with chronic obstructive pulmonary disease (COPD): An economic rapid review: Health Quality Ontario 2015;

11. Houchen-Wolloff L, Sandland CJ, Harrison SL, Menon MK, Morgan MD, Steiner MC, et al. Ventilatory requirements of quadriceps resistance training in people with COPD and healthy controls. Int J Chron Obstruct Pulmon Dis 2014; 9:589. doi: 10.2147/COPD.S59164.

12. Khosravi M, Tayebi SM, Safari H. Single and concurrent effects of endurance and resistance training on pulmonary function. Iran J Basic Med Sci 2013; 16(4):628.

13. Edvardsen E, Skjønsberg OH, Holme I, Nordsletten L, Borchsenius F, Anderssen SA. High-intensity training following lung cancer surgery: A randomised controlled trial. Thorax 2015; 70(3):244-50. doi: 10.1136/thoraxjnl-2014-205944.

14. Zambom-Ferraresi F, Cebollero P, Gorostiaga EM, Hernández $M$, Hueto J, Cascante J, et al. Effects of combined resistance and endurance training versus resistance training alone on strength, exercise capacity, and quality of life in patients with COPD. J Cardiopulm Rehabil Prev 2015; 35(6):446. doi: 10.1097/HCR.0000000000000132.

15. Vonbank K, Strasser B, Mondrzyk J, Marzluf BA, Richter B, Losch $S$, et al. Strength training increases maximum working capacity in patients with COPD-randomized clinical trial comparing three training modalities. Respir Med 2012; 106(4):557-63. doi: 10.1016/j.rmed.2011.11.005.

16. Silva CM, Gomes Neto M, Saquetto MB, Conceição CS, Souza-Machado A. Effects of upper limb resistance exercise on aerobic capacity, muscle strength, and quality of life in COPD patients: a randomized controlled trial. Clin Rehabil 2018; 32(12):1636-44. doi: 10.1177/0269215518787338.

17. Liao WH, Chen JW, Chen X, Lin L, Yan HY, Zhou YQ, et al. Impact of resistance training in subjects with COPD: A systematic review and meta-analysis. Respir Care 2015; 60(8):1130-45. doi: 10.4187/respcare.03598.

18. Li N, Li P, Lu Y, Wang Z, Li J, Liu X, et al. Effects of resistance training on exercise capacity in elderly patients with chronic obstructive pulmonary disease: A meta-analysis and systematic review. Aging Clin Exp Res 2020; 32(10):1911-22. doi: 10.1007/s40520-019-01339-8. 
19. de Lima FF, Cavalheri V, Silva BS, Grigoletto I, Uzeloto JS, Ramos D, et al. Elastic resistance training produces benefits similar to conventional resistance training in people with chronic obstructive pulmonary disease: Systematic review and meta-analysis. Phys Ther 2020; 100(11):1891-905. doi: 10.1093/ptj/pzaa185.

20. lepsen UW, Jørgensen KJ, Ringbaek T, Hansen H, Skrubbeltrang C, Lange P. A systematic review of resistance training versus endurance training in COPD. J Cardiopulm Rehabil Prev 2015; 35(3):163-72. doi: 10.1097/HCR.000000000000 0105. 